\title{
Future private car stock in China: current growth pattern and effects of car sales restriction
}

\section{Yu Gan, et al. [full author details at the end of the article]}

Received: 5 April 2019 / Accepted: 8 May 2019/Published online: 6 August 2019

(C) UChicago Argonne, LLC, Operator of Argonne National Laboratory 2019

\begin{abstract}
Car stock projection is essential to evaluating the energy and environmental impacts of private cars in China. Since the private car ownership rate in China has not reached its saturation level, limited and outdated data used in previous studies has resulted in high uncertainties regarding the functions of car ownership and significantly reduced the robustness of the projection of private car stocks. In this work, we estimate China's current growth pattern of private car ownership by analyzing more than 6300 pairs of private car ownership and income data collected from various official statistics at the national, provincial, and city levels in the period of 1997-2017. The dataset covers a much wider per-capita disposable income range than national-level data alone and allows us to make satisfactory projections of private car stocks in China up to 2040. We project that the private car stock in China could reach 403 million in 2040 , if the current growth pattern of car ownership continues. Significant discrepancies in private car ownership curves are observed for cities with and without car sales restrictions. Without car sales restrictions, we estimate that the private car stock would be even higher at 455 million by 2040, demonstrating the effectiveness of the current restriction policy in controlling car stocks in China. We further quantify the potential impacts of car sales restrictions on future car stock levels by implementing hypothetical national car sales caps. Results show that, although the private car stocks would still continue to grow before 2030, the stock levels would be stable at $\sim 280$ and $\sim 350$ million by 2040 for scenarios of 20 and 25 million sales caps, respectively. The impact of private car stock growth on energy consumption in China is also examined. Pump-to-wheels energy consumption of the private car fleet is projected to be 131, 147, 90, and 113 million tonnes of oil equivalent by 2040 for scenarios of the current growth pattern, no sales restriction, the 20 million sales cap, and the 25 million sales cap, respectively. Analysis reveals that private car sales restriction and vehicle population growth control could be an effective strategy for energy consumption reduction (thus greenhouse gas emission mitigation) in China, although the development of the automotive industry may be restrained.
\end{abstract}

Keywords Private car stock $\cdot$ Car sales $\cdot$ Projection $\cdot$ Sales restrictions $\cdot$ Energy consumption · China

Electronic supplementary material The online version of this article (https://doi.org/10.1007/s11027-01909868-3) contains supplementary material, which is available to authorized users. 


\section{Introduction}

For the past decades, the world has witnessed tremendous economic growth and an unprecedented scale of urbanization in China (Gan and Griffin 2018). Accompanying the economic development was the growth of private car stocks and sales. China has exceeded the USA to become the world's largest car sales market since 2008 (OICA 2015). The increased number of cars on the road has resulted in the growth of fuel demand, rising emissions of air pollutants and greenhouse gases, and severe traffic congestion (Gan et al. 2019). One of the prerequisites of tackling the above issues is a reliable projection of private car growth in China, which is the focus of the present study.

A number of studies have attempted to assess car growth in China (He et al. 2005; Hsieh et al. 2018; Huo and Wang 2012; Huo et al. 2007; Kobos et al. 2003; Wang and He 2000; Wang et al. 2006; Yan and Crookes 2009). In these studies, a widely recognized method of projecting private car stocks has been to assume an $S$-curve growth pattern of vehicle ownership that increases slowly in the beginning when economic levels are low, rises steeply subsequently, and gradually approaches a saturation level (Lu et al. 2018). For example, Wang and $\mathrm{He}$ (2000) projected the vehicle stock in China based on historical reviews of the growth patterns of per-capita vehicle ownership versus per-capita gross domestic product (GDP) in developed countries. Wang et al. (2006) used an $S$-shaped Gompertz function to model the relationship between per-capita vehicle ownership and per-capita GDP of China in projecting the vehicle stock through 2050. Huo and Wang (2012) took car purchase prices into account when analyzing the relationship between income level and the private car ownership, and projected that China's private car stock would reach 420-500 million by 2040 . Depending on Huo and Wang (2012)'s approach, Hsieh et al. (2018) recently conducted Monte Carlo simulations to analyze the uncertainties in the vehicle adoption trajectory. Based on the limited national car ownership data, they concluded that China's private car stock projection would have large uncertainties, varying from 200 to 700 million by 2040 (Hsieh et al. 2018).

The high uncertainty in private car ownership projection models stems from China's short period of data accumulation and the relatively poor data availability. Particularly, the National Bureau of Statistics of China (NBSC), the main data source of national private car ownership by income group in previous studies (Hsieh et al. 2018; Huo and Wang 2012; Huo et al. 2007; Wang et al. 2006), has stopped reporting the statistics of private car ownership by income group at the national and regional levels since 2012 (NBSC 1981-2017). This fundamentally caused nearly all previous studies to use outdated historical data in their car ownership models when projecting car stocks in China. For example, the most recent study by Hsieh et al. (2018) still used the household survey data of private car ownership by income group prior to 2010, before the time when income and car ownership grew dramatically in China.

Another shortcoming of previous studies is that arbitrary ultimate saturation levels of car ownership needed to be assumed because national private car ownership in China is still in its rapidly growing stage and is far from saturation. As mentioned earlier, the response of car ownership to economic parameters in most of the previous studies was expressed as $S$-shape functions, in which the ultimate saturation level of car ownership was a key parameter. The car ownership saturation level can be affected by factors such as population density, urban development patterns, and government's decisions to control car stock. In previous studies, a saturation level in the range of 200-800 cars per thousand people was normally selected for China (Dargay and Gately 1999; He et al. 2005; Huo and Wang 2012; Kobos et al. 2003; Lu et al. 2018; Wang et al. 2006). For example, Huo and Wang (2012) assumed two saturation 
levels in their car ownership growth model that were close to European ( $\sim 500$ cars per thousand people) and Japanese ( $\sim 400$ cars per thousand people) growth patterns. Dargay and Gately (1999) assumed that all countries (including China) follow the same car growth pattern with a saturation level of 620 cars per thousand people. Kobos et al. (2003) used data from other East Asian areas (including South Korea, Taiwan, and Japan) to estimate the saturation level of China as being 292 vehicles per thousand people. Hsieh et al. (2018) left this question open but performed a Monte Carlo simulation with saturation levels in the range of 200-800 cars per thousand people. These arbitrarily selected saturation levels for car ownership could potentially lead to errors and bias when projecting car stocks in China.

Instead of using outdated national car ownership data and making arbitrary judgments or analogies to other countries, in the present study, we constrain the relationship between car ownership and per-capita disposable income in China by conducting a regression of more than 6300 pairs of sample data in the period of 1997-2017 from various official statistics at the national, provincial, and city levels to derive China's specific car ownership function. In particular, the dataset covers per-capita disposable income levels up to 110,000 Renminbi (RMB, Chinese currency, 2015 constant), which can make satisfactory starting points for the projection of car stock in 2040 (estimated per-capita disposable income of 88,000 in $2015 \mathrm{RMB}$ ).

Using the analysis of the most updated dataset, the study also discusses the potential effects of sales restrictions on private car growth. To alleviate the pressure from air pollution and traffic congestion, a number of Chinese cities have begun to restrict private car sales. Sales restriction will directly affect car stock growth, which is a key factor that should be considered but has not been discussed thoroughly in previous studies.

In summary, the present study (1) collects private car ownership and per-capita disposable income data from the national, provincial, and city levels for the period 1997-2017 to regress China's specific car ownership model, (2) discusses the potential effects of car sales restriction regulations, and (3) projects the private car stock, sales, and associated energy consumption through 2040. In these ways, the study provides the latest insight on private car growth in China.

\section{Methods and data}

\subsection{Projection of private car stock}

Per-capita income has been revealed to be the primary factor influencing the car ownership rate (Dargay and Gately 1999; Jong et al. 2004). In our previous work, we developed a car stock projection model for China that simulates the private car ownership on an income-level basis by taking car purchase prices into account (Huo and Wang 2012; Lu et al. 2018). The total private car stock in year $m\left(\right.$ Stock $\left._{m}\right)$ is calculated by:

$$
\operatorname{Stock}_{m}=\mathrm{TP}_{m} \int_{x=0}^{\infty}\left[f(x)_{m} \cdot s\left(\mathrm{VPP}_{m}\right)\right] d x
$$

where $\mathrm{TP}_{m}$ represents the total population in year $m, x$ represents the per-capita disposable income in constant $2015 \mathrm{RMB}, f(x)_{m}$ is the disposable income distribution function in year $m$, and $s\left(V P P_{m}\right)$ is the private car ownership per thousand people as the function of the vehicle purchasing power (VPP). VPP is the quotient of per-capita disposable income $x$ and the vehicle price index (VPI) (Hsieh et al. 2018; Huo and Wang 2012). VPI reflects the differences in car prices over the years and is estimated as a ratio of car prices in year $m$ to those of the same models in the year 
2004. VPP is used in the car ownership function $s\left(V P P_{m}\right)$ because it represents the car-priceadjusted income level and can better model car ownership growth in China, where vehicle prices, incomes, and inflation have great disparities (Huo and Wang 2012; Lu et al. 2018).

The sigmoid-shaped Gompertz function has been widely used to simulate the relationship between private car ownership and income levels (Hsieh et al. 2018; Huo and Wang 2012; Jong et al. 2004). Most of the Gompertz functions previously used contain shape parameters lacking in physical meaning, making it difficult to estimate start values for these parameters in a regression analysis (Zwietering et al. 1990). Here, we use a modified Gompertz function to solve this problem and improve the regression efficiency:

$$
s\left(\mathrm{VPP}_{m}\right)=s\left(x / \mathrm{VPI}_{m}\right)=A \cdot \exp \left[-\exp \left(\frac{\mu \cdot e}{A} \cdot\left(\lambda-x / \mathrm{VPI}_{m}\right)+1\right)\right]
$$

In Eq. (2), all three parameters ( $A, \lambda$, and $\mu$ ) have physical meanings. $A$ represents the ultimate saturation level, i.e., the maximum private car ownership per thousand people; $\lambda$ is the length of the lag phase of the sigmoid curve, meaning the income level at which car ownership starts to grow; and $\mu$ is the maximum growth rate of car ownership (Kahm et al. 2010). In using Eq. (2), the parameters $A, \lambda$, and $\mu$ are determined by fitting the historical data for VPI, percapita disposable income $x$, and car ownership $s$ collected at the national, province, and city levels with weighting factors of the corresponding private car stocks.

Various probability distribution functions have been tested for fitting the effect of income disparity in previous studies (Chen et al. 2015; McDonald 2008; McDonald and Ransom 1979; Souma 2001; Zhang et al. 2013). For China specifically, Chen et al. (2015) analyzed household income data from 2005 to 2012, and compared the fitting effects of eight distribution functions. It was demonstrated that the log-logistic distribution has the best fitting effect among other two-parameter distribution functions. We adopt the log-logistic function as the income distribution function $f(x)_{m}$ for China:

$$
f(x)_{m}=\frac{b_{m} \cdot x^{b_{m}-1}}{a_{m}{ }^{b_{m}} \cdot\left(1+\left(x / a_{m}\right)^{b_{m}}\right)^{2}}
$$

where $a_{m}$ and $b_{m}$ are the scale and shape parameters, respectively, of the log-logistic distribution in year $m$. For the log-logistic distribution, the parameters $a_{m}$ and $b_{m}$ in year $m$ can be derived from the mean disposable income $\left(D_{m}\right)$ and the Gini index $\left(G_{m}\right.$, a widely used indicator of income inequality). The values of these parameters will be detailed in Sect. 2.3 below.

$$
\begin{gathered}
b_{m}=\frac{1}{G_{m}} \\
a_{m}=\frac{D_{m} \cdot \sin \left(\pi \cdot G_{m}\right)}{\pi \cdot G_{m}}
\end{gathered}
$$

\subsection{Private car ownership data at the national, province, and city levels}

Unlike previous studies that use outdated national car ownership data (national data by income group was discontinued after 2012) and make arbitrary assumptions about the ultimate saturation level of the car ownership function, we estimate China's private car ownership curve by fitting a large amount of car ownership data collected at multiple (national, province, and city) levels 
weighted with the corresponding car stocks. These data were derived and compiled from surveys of Chinese urban households at different income levels by the Statistics Bureaus of various local authorities. Figure 1 shows the data coverage of the private car ownership and the corresponding car stocks collected in this study. A full list of references for data sources of individual provinces and cities can be found in Table 1 of the Supporting Information. In total, we collected more than 6300 pairs of private car ownership and per-capita disposable income data in the period of 19972017. The data set covers all national- and provincial-level data reported by the official government and data of top 54 cities that possess the most cars in China (total car stocks of 79 million in 2016, $\sim 53 \%$ of the national stock). From the income range point of view, the data set covers percapita disposable income levels up to $110,000 \mathrm{RMB}$ (2015 constant), which is significantly wider than the range up to $\sim 60,000 \mathrm{RMB}$ for the pre-2012 national-level data (data used in previous studies), and can make satisfactory references for the projection of car stock in 2040 (estimated per-capita income of $\sim 88,000$ in $2015 \mathrm{RMB}$ ).

\subsection{Data for population, per-capita disposable income, vehicle price, and the Gini index}

According to previous discussion, the private car stock is calculated based on projections of total population, disposable income per capita, the VPI, and the Gini index. For population and per-capita disposable income, we develop different scenarios to reflect potential social and economic development in China. The future population is obtained from United Nations' World Population Prospects (UN 2017), where the low, medium, and high estimates correspond to the low, medium, and high fertility projections, respectively. A review of the historical data reveals a strong linear relationship (coefficient of determination $R^{2}=0.993$ ) between per-capita disposable income and per-capita GDP (NBSC 1981-2017). We thus estimate the per-capita disposable income based on the per-capita GDP projection. Here, the

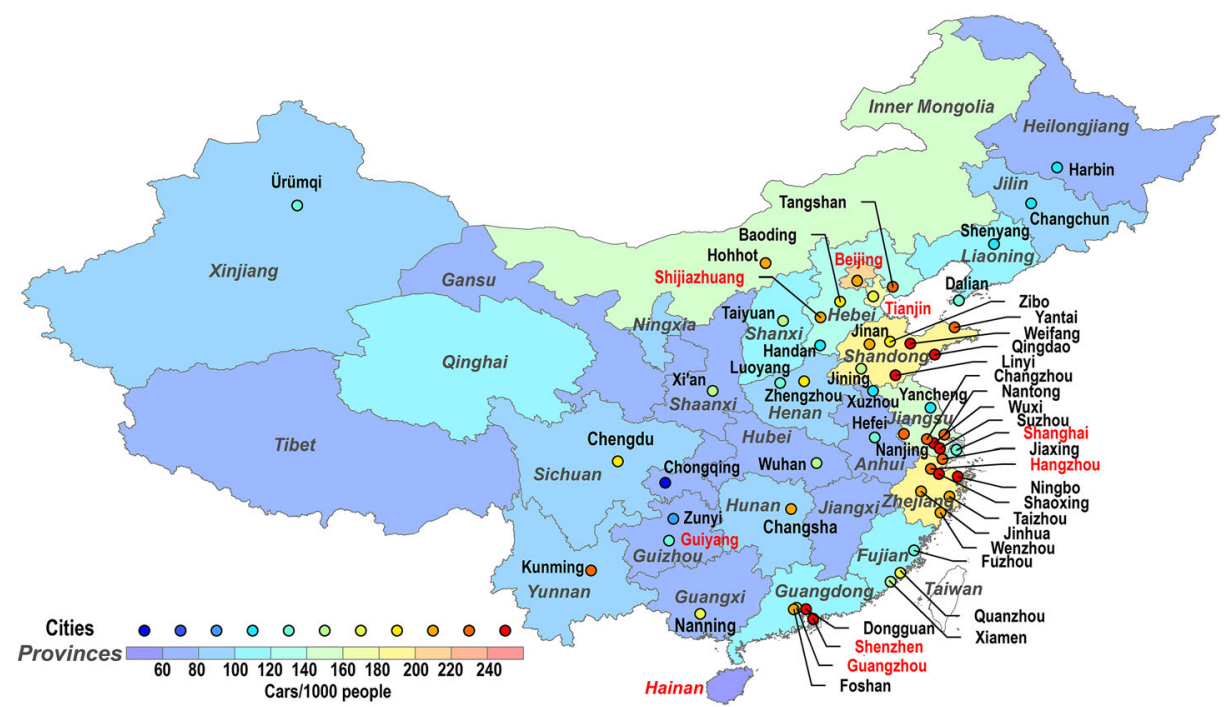

Fig. 1 Private car ownership data coverage of provinces and cities. Provinces and cities are colored to show their car ownership levels in 2016; cities and provinces shown in red impose car sales restrictions 
Table 1 Projections of population, GDP, vehicle price index (VPI), and Gini index

\begin{tabular}{|c|c|c|c|c|c|c|c|c|}
\hline & \multicolumn{3}{|c|}{ Total population (million) } & \multicolumn{3}{|c|}{ GDP (trillion 2015 RMB) } & \multirow[t]{2}{*}{ VPI } & \multirow[t]{2}{*}{ Gini index } \\
\hline & Low & Medium & High & Low & Medium & High & & \\
\hline 2020 & 1412 & 1425 & 1437 & 95 & 95 & 95 & 0.294 & 0.450 \\
\hline 2025 & 1409 & 1439 & 1469 & 123 & 124 & 126 & 0.276 & 0.425 \\
\hline 2030 & 1391 & 1441 & 1491 & 155 & 159 & 166 & 0.269 & 0.400 \\
\hline 2035 & 1364 & 1434 & 1503 & 189 & 198 & 212 & 0.274 & 0.390 \\
\hline 2040 & 1329 & 1417 & 1508 & 227 & 240 & 264 & 0.287 & 0.380 \\
\hline
\end{tabular}

future GDP in China is projected based on the International Energy Outlook by the Energy Information Administration (EIA 2017). The low, medium, and high estimates correspond to EIA's low, reference, and high economic development scenarios, respectively.

VPI values are obtained from previous studies (Huo and Wang 2012; Lu et al. 2018), in which the future VPI was estimated based on a comparison of the historical car price trend for the United States and China. Car prices in China decreased dramatically (approximately $80 \%$ ) since 1997 (Huo and Wang 2012; Lu et al. 2018), which is similar to the trend of the early motorization stage of the USA from 1900 to 2020 (Williams et al. 2017). Like the trend in the USA from 1920 to 1940, the VPI of China is assumed to decrease until 2030 (i.e., corresponding to the decreasing VPI period of 1920-1930 in the USA) and then increase slightly until 2040. We follow Huo and Wang (2012)'s projection that Gini index will continue to decrease until 2040. Table 1 shows the projections of total population, GDP, VPI, and Gini index used in the study.

As mentioned before, the disposable income distribution functions are estimated with the mean disposable income and the Gini index using Eqs. (3)-(5). Figure 2 shows the estimated disposable income distribution functions for China from 2010 to 2040. By 2040, per-capita disposable income is projected to increase significantly, and more than $80 \%$ of the population's income is postulated to be higher than the average level of 2010. This further demonstrates the importance of analyzing the car ownership levels of the high-income population in making the private car stock projection in China.

\subsection{Private car sales}

Theoretically, the private car stock in year $m$ is the sum of all cars sold previously that are still on road:

$$
\operatorname{Stock}_{m}=\sum_{j=0}^{n}\left(\operatorname{Sales}_{m-j} \cdot r_{j}\right)
$$

where $r_{j}$ represents the private car survival rate at age $j$, Sales ${ }_{m-j}$ represents the car sales of year $m-j$, and $n$ is the possible longest car service year. Equation (6) can be reorganized to back-calculate car sales from stocks in year $m$ as:

$$
\text { Sales }_{m}=\frac{\operatorname{Stock}_{m}-\sum_{j=1}^{n}\left(\operatorname{Sales}_{m-j} \cdot r_{j}\right)}{r_{0}}
$$

In this work, the historical car sales are collected from China's automotive industry (CATRC 1991-2016). We follow Lu et al. (2018)'s treatment, assuming that the survival rate $r$ of private cars at age $j$ can be expressed with a two-parameter logistic function: 


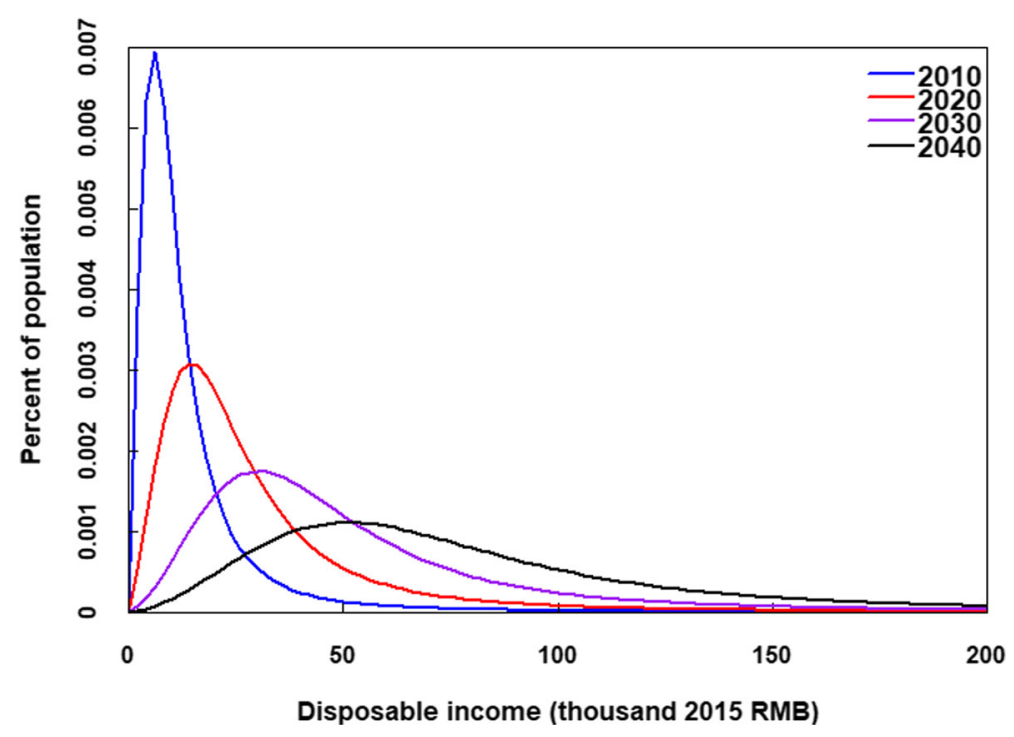

Fig. 2 Estimated disposable income distribution functions in China from 2010 to 2040

$$
r_{j}=\frac{1}{1+\exp \left[\sigma \times\left(\frac{j}{L_{50}}-1\right)\right]}
$$

where $L_{50}$ is the vehicle age at which $50 \%$ of the cars have retired, and $\sigma$ is a shape factor related to the onset of significant car retirement. Based on historical sales and stock data, $L_{50}$ and $\sigma$ were determined to be 13.3 and 7.1, respectively ( $\mathrm{Lu}$ et al. 2018).

In this study, we also develop scenarios with fixed annual sales caps to discuss the potential effects of car sales restrictions. For those scenarios, Eq. (6) instead of Eq. (1) is used to project private car stocks.

\subsection{Energy consumption of private car fleet}

In this work, we use the China vehicle fleet model developed by Argonne National Laboratory ( $\mathrm{Lu}$ et al. 2018) to evaluate the energy and environmental impacts of projected private car stocks and sales in China. The model calculates the pump-to-wheels (PTW) energy consumption by vehicle technology, fuel type, and vehicle age as the product of the corresponding vehicle stock, vehicle kilometers traveled (VKT), and fuel consumption rate (FCR):

$$
\text { Energy }_{m}=\sum_{k} \sum_{i} \sum_{j}\left(\operatorname{Stock}_{i, k, j, m} \cdot \mathrm{VKT}_{i, k, j, m} \cdot \mathrm{FCR}_{i, k, j, m}\right)
$$

where $k, i$, and $j$ represent fuel type, vehicle technology, and vehicle age, respectively. Except for stocks and sales of private cars, other parameters in the Base Case of the China vehicle fleet model are used directly. The future FCRs and market shares of individual vehicle technologies in the Base Case of the model are configured based on the Technology Roadmap for Energy Saving and New Energy Vehicles released by Chinese Society of Automotive Engineers (CSAE 2016). Detailed methods can be found in Lu et al. (2018). 


\section{Results and discussion}

\subsection{Validation of the private car stock projection model}

A significant difference between the current work and previous studies in projecting China's car stocks is that we estimate China's specific private car ownership curve by fitting not only national car ownership and income data, but also a large amount of data collected at the province and the city levels. This will overcome the lack of income-grouped national data after 2012 due to the discontinued statistics, capture the characteristics of private car ownership in recent years, and expand the private car ownership curve to much higher income levels, which have been demonstrated to be important to the private car stock projection in China (Fig. 2). We use a modified Gompertz function (Eq. (2)) to achieve a weighted fit for data of different ranges, and the weighting factors are the corresponding private car stocks of individual data points. The embedded assumption here is that the weighted average ownership curve of the historical province- and city-level data can represent the historical and future national car ownership, if the provincial and city data well represent the national car stock. For example, more than 6300 data points collected in this work cover all provinces and the top 54 cities that possess most cars in China (these cities possessed $~ 53 \%$ of the car stock in 2016).

To verify this assumption, we conduct a validation experiment to test whether historical province- and city-level data before a certain year can be used to derive historical national averages and capture the trend of national averages in the following years. Figure 3a shows the private car ownership data at the province and city levels for the period of 1997-2010. Weighted regression curves and the corresponding 95\% confidence intervals (CI) based on these pre-2010 data are shown in Fig. 3a, b. Clearly, the national private car ownership data before 2010 fall in the $95 \%$ CI range of the weighted regression line derived from province and city data. Additionally, national private car ownership values of the post-2010 period (20112018, non-income-grouped car ownership data after 2012) also follow the same curve. The validation test demonstrates that the method proposed in this work can be used to estimate the national private car ownership curve in China and can also be used to project private car stocks within the covered VPP range, if the current growth pattern of car ownership continues.

\subsection{Private car ownership curve of the current growth pattern}

Figure 4 shows the private car ownership curve regressed from more than 6300 car ownership data points collected in this work. As discussed in the previous section, this curve can be considered as the current growth pattern for private car ownership in China. The dataset covers the VPP range up to 350,000 (2015 RMB), which exceeds the estimated 2040 average VPP of $\sim 308,000$ (2015 RMB). Therefore, along with the total population and the per-capita disposable income projections, the regressed curve can provide reasonable private car stock estimates up to 2040 , if the car growth continues following the current pattern.

It should be noted that, although an ultimate saturation level $A$ can be obtained by regressing data points with Eq. (2), it potentially contains large uncertainty due to the limited number and incomplete representation of the data points in the high VPP range. In other words, the current dataset still cannot allow us to estimate the saturation level of private car ownership in China accurately, but it can help us constrain the private car ownership curve in the VPP range up to at least $\sim 250,000$ (2015 RMB, Fig. 4), which can significantly reduce the uncertainties of the stock projections in China. 
Nevertheless, the national average private car ownership saturation level in China is potentially lower than the USA's level of $\sim 800$ (Davis et al. 2009), the European countries' levels of 450-600 (EC 2010), and Japan's level of 440 (SBJ 2007). There could be many reasons for the possible lower private car ownership rate in China. First, the high population density and relatively limited resources (e.g., parking lots) on a per-capita basis restrain car ownership growth in the country. The comparison between countries in Western Europe and North America showed that the saturation levels of countries with high population densities are relatively low (Huo et al. 2007). Second, China has devoted great efforts to improving public transportation systems, including the construction of urban subway systems and the world's largest high-speed railway network, which provide more efficient and convenient travel options and reduce the demand for private cars (Huo et al. 2015; Yin et al. 2015). These efforts have diverted the country's transportation development from the dramatic growth of private cars to the improvement of the public transit system. Third, as the issues of air pollution and traffic congestion become more prominent, many cities in China have adopted restrictive policies on private car sales to limit the growth of private car stocks. This will be discussed in the next section.

\subsection{Effect of car sales restrictions}

By the end of 2018, eight cities and one province in China have implemented car sales restrictions. Shanghai was the first city to begin restrictions in 1994, while other cities did not set the restrictions until 2011 or later, when the air pollution and traffic congestion problems became prominent. After 2011, with the increase in the number of cities adopting restriction policies, the car ownership level thresholds at which restrictions started became lower. For example, Beijing began to restrict private car sales when car ownership reached $\sim 150$ per thousand people in 2011 (BSB 2012); Tianjin started the restriction when car ownership was 130 per thousand people in 2013 (TSB 2014), while Hainan Province began its restriction when the car ownership was only around 60 per thousand people in 2018 (HSB 2018). It can be postulated with these recent trends that car sales restrictions will likely continue to expand in China in the near future.

The implementation and effects of car sales restrictions vary from city to city. The most common measure for local authorities is to directly control the number and the
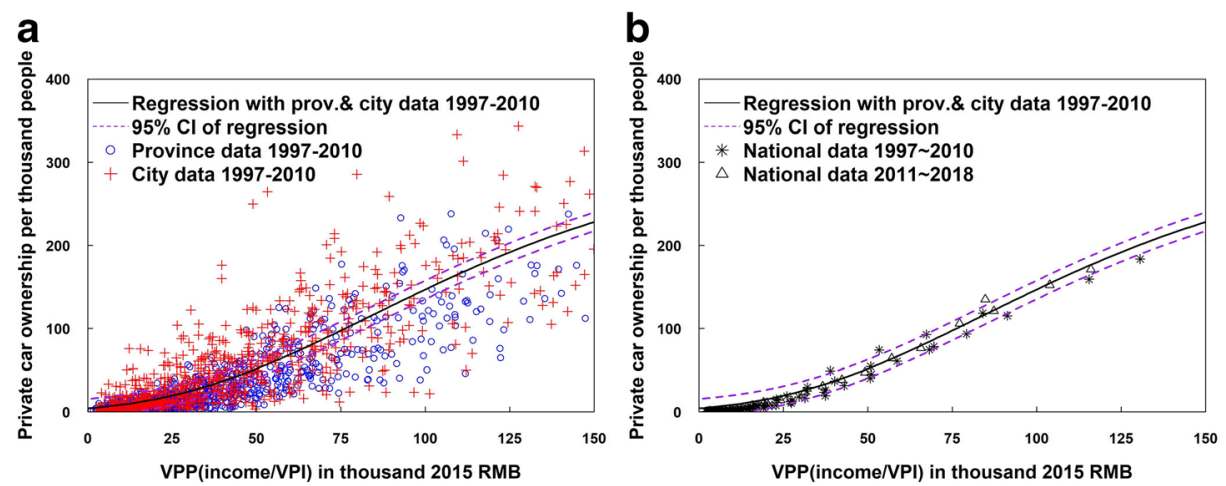

Fig. 3 Car ownership function regressions. a Weighted regression with province- and city-level data for 19972010; (b) 1997-2010 province and city regression versus national private car ownership for 1997-2018 


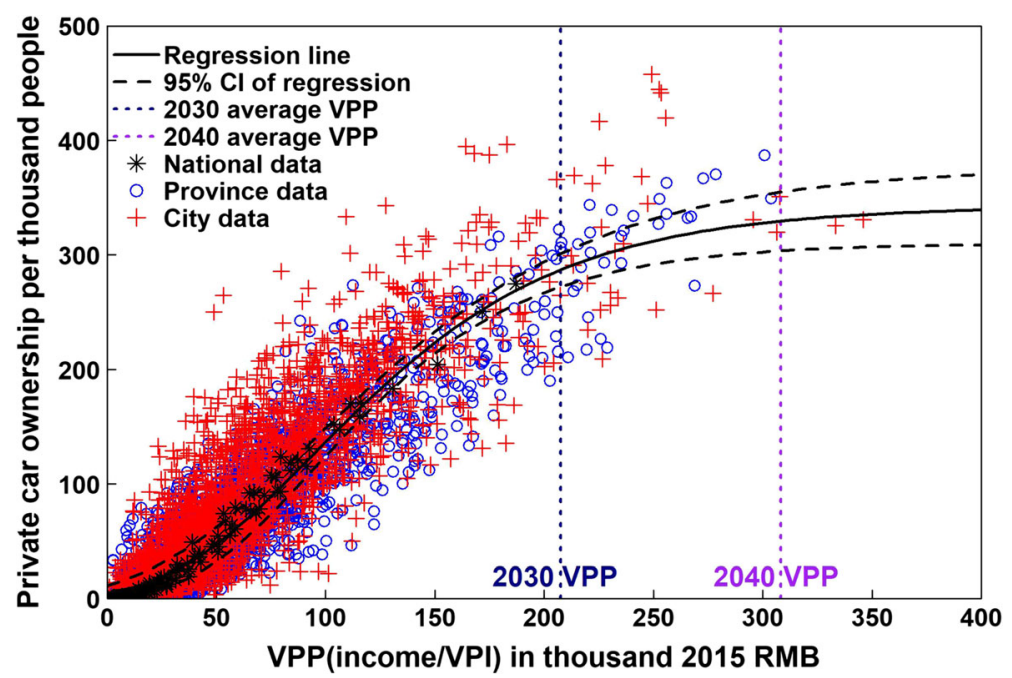

Fig. 4 Private car ownership curve regressed from the national-, province-, and city-level data for 1997-2017

allocation of new vehicle license plates, thereby restricting the sales of private cars. Shanghai limits the number of license plates issued each year and holds public auctions to sell them. In the year 2017 , the number of new license plates issued was $\sim 132$ thousand, while the total population of Shanghai is $\sim 24$ million. The shortage of license plates made the auction price extremely high, $\sim 90,000$ RMB $(\sim 13,000$ US dollar $)$ in 2017. The high cost of car plates significantly limits people's ability and willingness to own cars, lowering the private car ownership of the city. In 2016, the car ownership of Shanghai was 136 per thousand people, which was much lower than Beijing's level of 226 per thousand people and the nearby city Suzhou's level of 285 per thousand people. As shown in Fig. 5, because of the long-term sales restriction, the car ownership growth curve of Shanghai is unique and much lower than the growth curve of other cities or provinces in China.

Since 2011, Beijing has restricted car sales by setting a fixed quota of new car license plates. In 2011, the quota of new license plates was set as 240 thousand (the annual number of car sales in the previous year was $\sim 600$ thousand), and it continues to decrease. In 2018, the new vehicle registration was only 100 thousand. Unlike Shanghai, the new car license plates in Beijing are allocated by a lottery process. Guangzhou started restrictions in 2012 and constrained the number of new car license plates to 120 thousand yearly. Ten percent of new license plates of Guangzhou is allocated to "clean energy vehicle" (e.g., battery electric vehicles), $40 \%$ is determined by a lottery system, and the remaining $50 \%$ is determined by auction. Adopting similar ways of allocating the quota of new license plates through both lotteries and auctions, the cities of Tianjin, Hangzhou, and Shenzhen started their restrictions in 2013, 2014, and 2015, respectively. Car sales restrictions in Guiyang and Shijiazhuang started during 2011 and 2013, respectively, although they were permissive compared to other cities. Guiyang restricts new car registration in some specific districts having serious traffic congestion, and Shijiazhuang forbids families to own a third car. In 2018, Hainan became the first province in China to implement car sales restrictions. This means that, for the first time, 
car sales restrictions were extended to rural and underdeveloped areas, in addition to urban areas.

Although the car ownership curves of the other eight regions have not shown changes that were as dramatic as Shanghai, they are different from the curves of cities without sales restrictions, demonstrating the effectiveness of the restriction policy. Figure 6 compares the car ownership curves among cities with and without car sales restrictions. Here, only the top 20 cities with the highest private car stocks in China are included in the comparison to minimize the potential impacts of other factors, such as economic development and urban infrastructure. Obviously, cities with sales restrictions have lower car ownership rates than cities without sales restrictions. The difference is more prominent at the high VPP levels. The car ownership curve for cities with car sales restrictions shows the trend of a gradual saturation at high VPP levels, while apparently the saturation point has not been reached for cities without sales restrictions.

\subsection{Projection of private car stocks and sales}

Figure 7 and Table 2 show the projected private car stocks and sales for China through 2040 under different scenarios. Here, we consider five scenarios: (1) "current growth pattern," which uses the private car ownership curve shown in Fig. 4; (2) "no sales restriction," which uses the ownership curve for cities without car sales restriction in Fig. 6; (3) "Shanghai mode," which uses the ownership curve for Shanghai in Fig. 5, representing the extremely low limit of private car stocks; (4) an annual private car sales cap of 20 million; and (5) an annual private car sales cap of 25 million, to explore the effects of the expanding car sales restrictions and hypothetical national sales caps on the future car stock in China.

As shown in Fig. 7, if the growth of private car stocks in China continues to follow the current ownership pattern, there would be 346 and 403 million private cars in China by 2030 and 2040, respectively, about 1.8 and 2.1 times of the stock level in 2018 . The uncertainty range of the projection for 2040 is about $\pm 15 \%$ of the mean estimate, reflecting the $95 \%$ CIs of

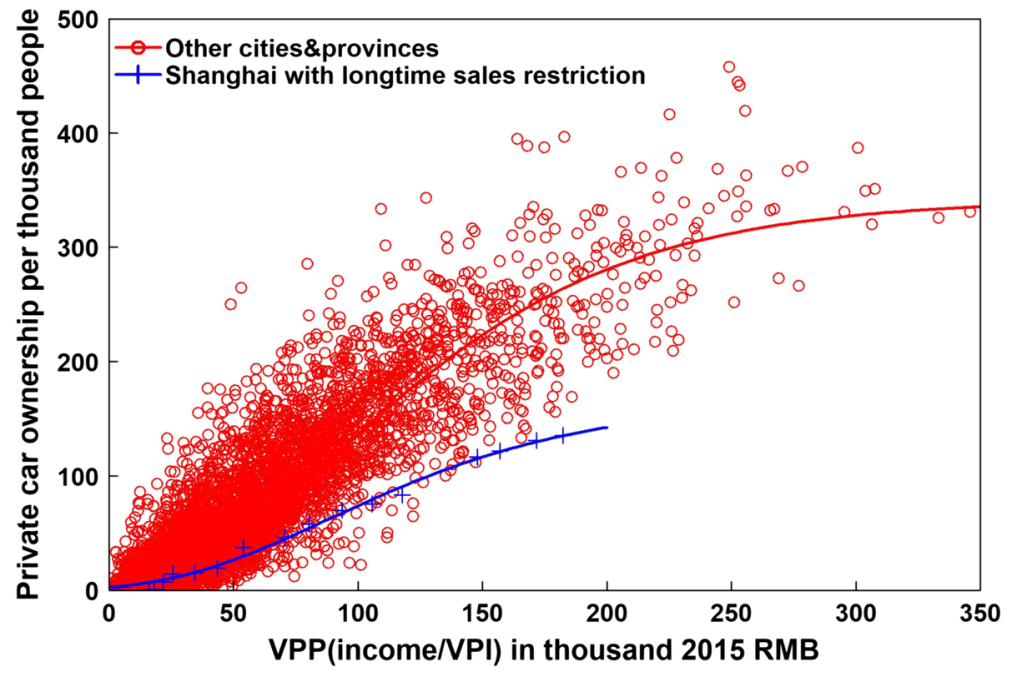

Fig. 5 Private car ownership curve of Shanghai vs. other cities and provinces 


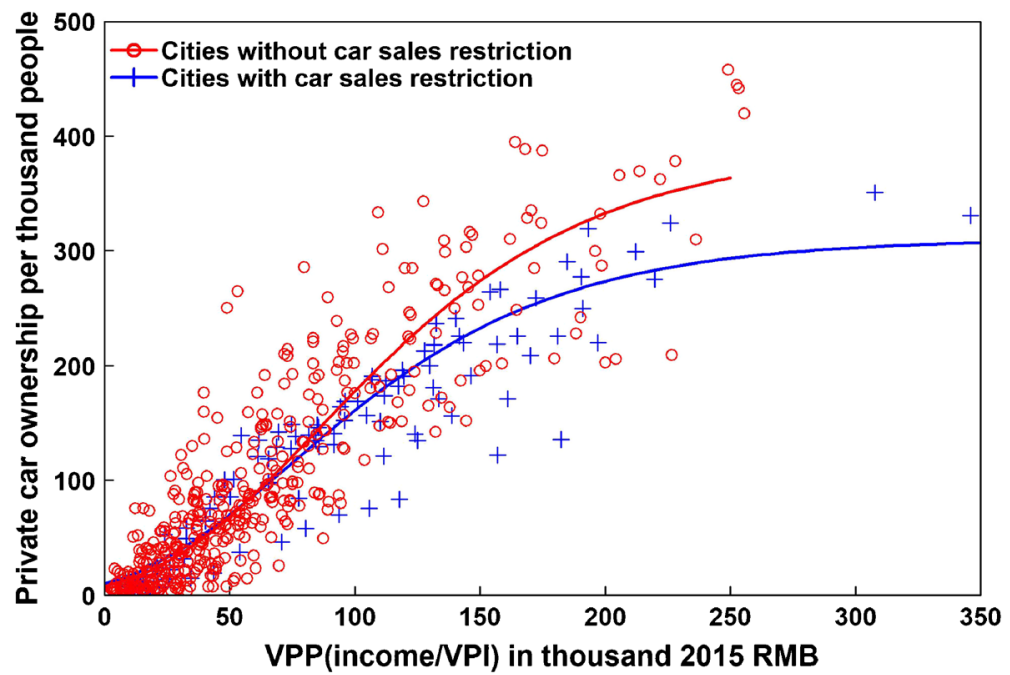

Fig. 6 Comparison of car ownership curves among cities with and without car sales restrictions

the car ownership curve in Fig. 4 and the variations of social and economic indicators in Table 1. If there is no car sales restriction, the private car stock would reach 384 (343-432) and 455 (394-528) million by 2030 and 2040, respectively, about $12 \%$ higher than the current growth pattern scenario. This clearly demonstrates the effectiveness of the current car sales restriction policies implemented in individual cities and provinces on the control of car stocks in China. The "Shanghai mode" represents a hypothetical scenario, assuming that China had implemented a similarly aggressive national sales restriction as Shanghai did since its very early motorization stage. Under this scenario, we estimate that the private car stocks in China would be only 193 (181-208) million by 2040, about the same as the current stock level.

The "no sales restriction" and "Shanghai mode" scenarios demonstrate the significant impacts of the sales restriction on future private car stock growth in China. Details of how the regulation is implemented, including the scope, the object, and the car ownership rate when the restriction starts, are all important factors that change the magnitude of the regulation's impacts. A restriction starting from a relatively low car ownership level would significantly suppress the growth of private car stocks, as is proved in the case of Shanghai. The proactive intervention of Shanghai was recognized and adopted by Hainan Province in implementing a sales restriction policy when its car ownership rate was only $\sim 60$ per thousand people. By subsidizing the construction of public transportation through revenue acquired from auctioning a limited number of private car licenses, the focus of transportation system development was diverted from private car promotion to public transportation improvement. This might be the guide for future implementation of sales restriction regulations in China. Therefore, the projection of private car growth in China must consider the effects of sales restrictions. For this reason, we develop another two annual sales cap scenarios that assume that a wide range of car sales restrictions will be implemented in China, leading to annual sales of private cars being controlled at the 20 and 25 million levels from now to 2040. Of note, private car sales in China during 2017 was 23 million (NBSC 2018). For these two scenarios, although the private car stocks are projected to continue growing before 2030, the projected car stocks would be stable at $\sim 280$ and $\sim 350$ million after 2030 for the sales caps of 20 and 25 million, respectively, providing China's car stock projection from another perspective. 


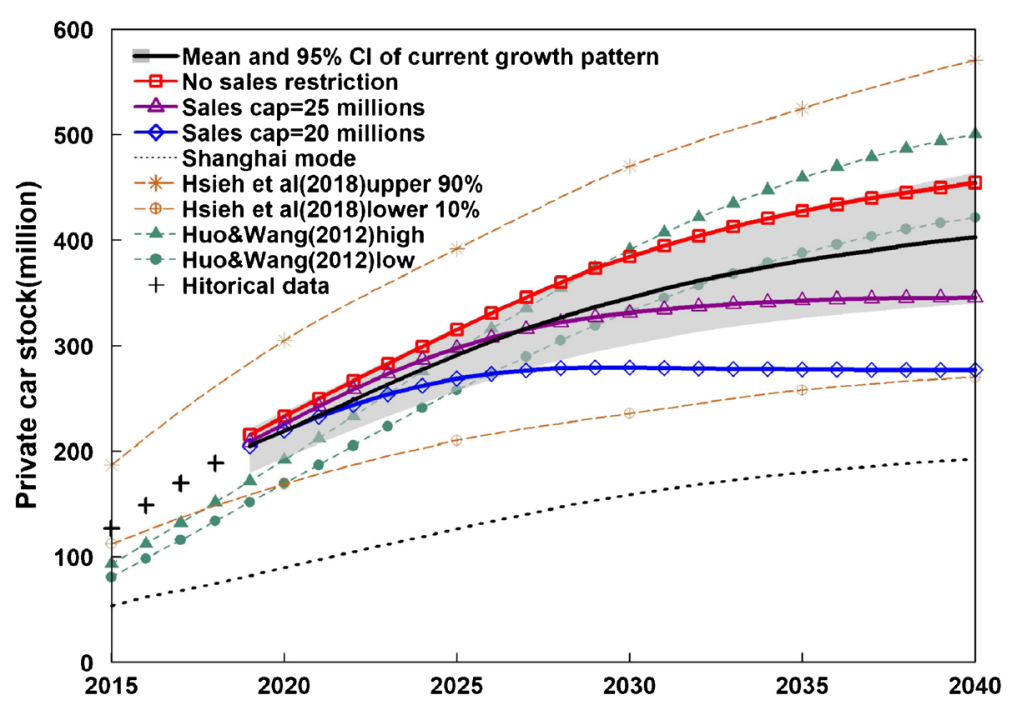

Fig. 7 Projections of private car stocks in China through 2040 under different scenarios. The uncertainty range is shown only for the current growth pattern scenario. The uncertainty ranges for other scenarios are listed in Table 2

Figure 7 also compares car stock projections of the present study with previous works. The projected car stock of 2040 in the "current growth pattern" scenario is lower than projections of both high and low car growth scenarios by Huo and Wang (2012), and the projection of the "no sales restriction" scenario is between the two scenarios of Huo and Wang (2012). The primary reason for the relatively low projection of the "current growth pattern" scenario is the lower-than-expected car ownership rate derived from the latest statistical data, while other reasons include different socioeconomic parameters used for the projections. One explanation of the lower-than-expected car ownership rate is the car sales restriction, which has not been considered in the previous study Huo and Wang (2012). This also explains why the projection of the "no sales restriction" scenario is close to the average projections of the two scenarios of Huo and Wang (2012). The projection uncertainties of the present study are smaller than that of Hsieh et al. (2018), because massive statistic data is used in the study to constrain the uncertain range of the car ownership growth curve.

Table 2 Projections of private car stocks and sales (million)

\begin{tabular}{llllll}
\hline & 2020 & 2025 & 2030 & 2035 & 2040 \\
\hline Stocks & & & & & \\
$\quad$ Current growth pattern & $219(194-237)$ & $291(257-318)$ & $346(301-384)$ & $381(326-430)$ & $403(340-464)$ \\
No sales restriction & $233(208-259)$ & $315(284-350)$ & $384(343-432)$ & $428(376-489)$ & $455(394-528)$ \\
Shanghai mode & $90(89-91)$ & $127(125-129)$ & $159(154-166)$ & $180(171-191)$ & $193(181-208)$ \\
Sales cap of 20 million & 219 & 269 & 279 & 277 & 277 \\
$\quad$ Sales cap of 25 million & 226 & 298 & 332 & 343 & 346 \\
Sales & & $27(25-29)$ & $29(27-32)$ & $29(26-33)$ & $29(27-33)$ \\
Current growth pattern & $22(19-25)$ & $30(28-32)$ & $33(30-36)$ & $33(30-36)$ & $34(31-37)$ \\
$\quad$ No sales restriction & $25(22-28)$ & 20 & 20 & 20 & 20 \\
Sales cap of 20 million & 20 & 25 & 25 & 25 & 25 \\
Sales cap of 25 million & 22 & & & & \\
\hline
\end{tabular}

Numbers in parentheses are the uncertain range of the projections 
Figure 8 and Table 2 further present the projections of annual private car sales in China under different scenarios. In contrast to previous projections of continuously increasing sales through 2040 (Huo and Wang 2012; IEA 2017), we project that annual private car sales would grow to 29 (26-33) million by 2030 and remain stable afterward in the "current growth pattern" scenario. Even in the "no sales restriction" scenario, the growth of private car sales would gradually slow down after 2030. The gradual slowdown of car sales agrees with the relatively lower projections of car stocks, reflecting the lower-than-expected car ownership rates in the latest statistics. Private car sales in China can be even lower than the present projections, if the sales restrictions expand nationwide in the future.

\subsection{Impacts on energy consumption}

Figure 9 shows projections of the energy consumption of the private car fleet in China under different scenarios. If the current car growth pattern continues, PTW energy consumption of the private car fleet would reach a peak of 143 million tonnes of oil equivalent (toe) before 2030 and gradually decrease afterward. Energy consumption of the "no sales restriction" scenario is higher than that of the "current growth pattern" scenario by $\sim 11 \%$ and $\sim 13 \%$ in 2030 and 2040, respectively. Annual sales cap scenarios would even lower the PTW energy consumption of the fleet to $\sim 90$ and $\sim 112$ million toe by 2040 for sales caps of 20 and 25 million, respectively. Gasoline would continue to be the dominant fuel for private cars, but its share would decrease as the vehicle fleet becomes electrified (Lu et al. 2018). Compared with previous studies, the energy consumption projections of the different scenarios in this study are much lower than the high car growth scenario by Huo et al. (2012) because our analysis suggests lower private car ownership rates. In contrast to previous projections of a continuously increasing trend of energy consumption through 2040, we project that the energy

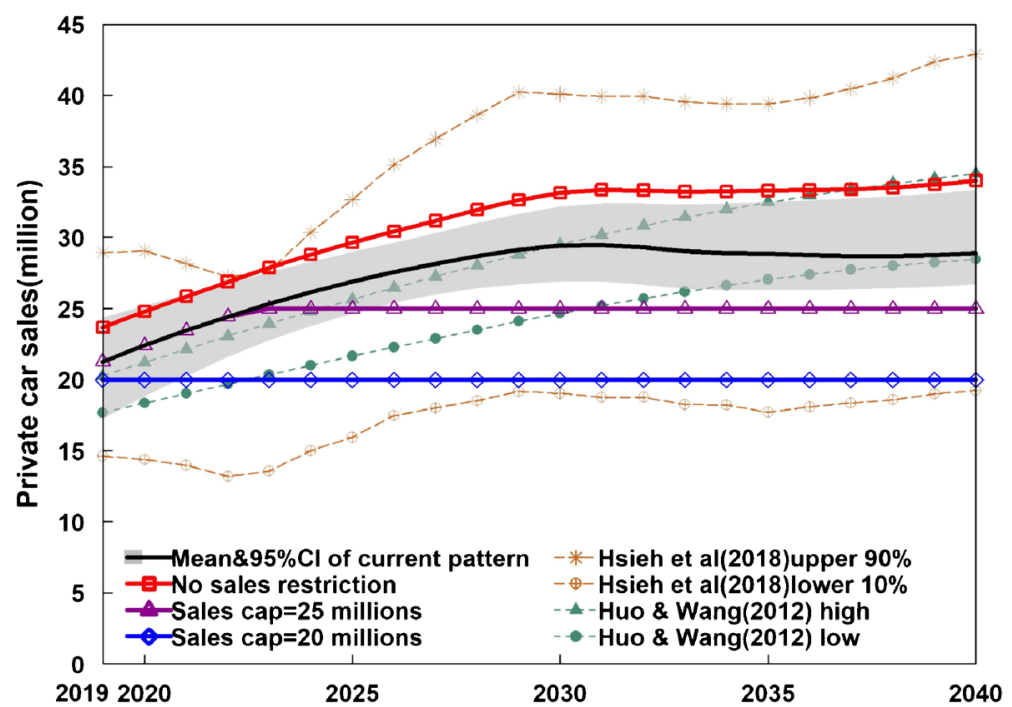

Fig. 8 Projections of private car sales in China through 2040 under different scenarios. The uncertainty range is shown only for the current growth pattern scenario. The uncertainty ranges for the "no sales restriction" scenario are listed in Table 2 
consumption of the car fleet would gradually decrease after 2030 because of the higher fuel economy of new cars (Lu et al. 2018).

\subsection{Sensitivity analysis}

We further conducted a sensitivity analysis on the projected private car stock in the "current growth pattern" scenario to see how independent parameters affect results. According to the discussion in Sect. 2.3, GDP, total population, the Gini index, and VPI are four independent parameters for the projection of the private car stock. As shown in Fig. 10, the impacts of changes in the mean values of the four parameters are analyzed for stock projections of different periods. GDP has a positive effect on private car stocks, while the positive effect gradually decreases in the long-term projections. The reason is that GDP has a positive relationship with per-capita disposable income, which is the main driving force of the growth of car ownership; however, the driving force of income weakens at high income levels. The effect of total population on the private car stock projection is negligible in 2020, but significant for long-term projections. By 2040, the total population would exceed the other three parameters and become the most important factor driving the uncertainties of the private car stock projections. Total population affects the projection model in two ways: First, it acts as a multiplier of the car ownership rate, thus producing a positive effect on the total car stock; second, it acts as a divisor of the GDP in calculating the per-capita GDP, and thus per-capita disposable income, producing a negative effect on the private car ownership rate. The two counter effects balance each other in the near-term stock projections, while the multiplier effect becomes prominent in the long-term projections due to the less sensitivity of income to car ownership rates at high-income levels. In 2040, a + 10\% variation in total population would lead to an increase in private car stock by 5.7\%. Both the Gini index and VPI have negative effects on projected private car stocks, and these effects would be less significant in the long-term projections. According to the sensitivity analysis, a $+10 \%$ variation in the Gini index or VPI in 2040 would result in a decrease of private car stock projections by $3.5 \%$ or $3.7 \%$, respectively.

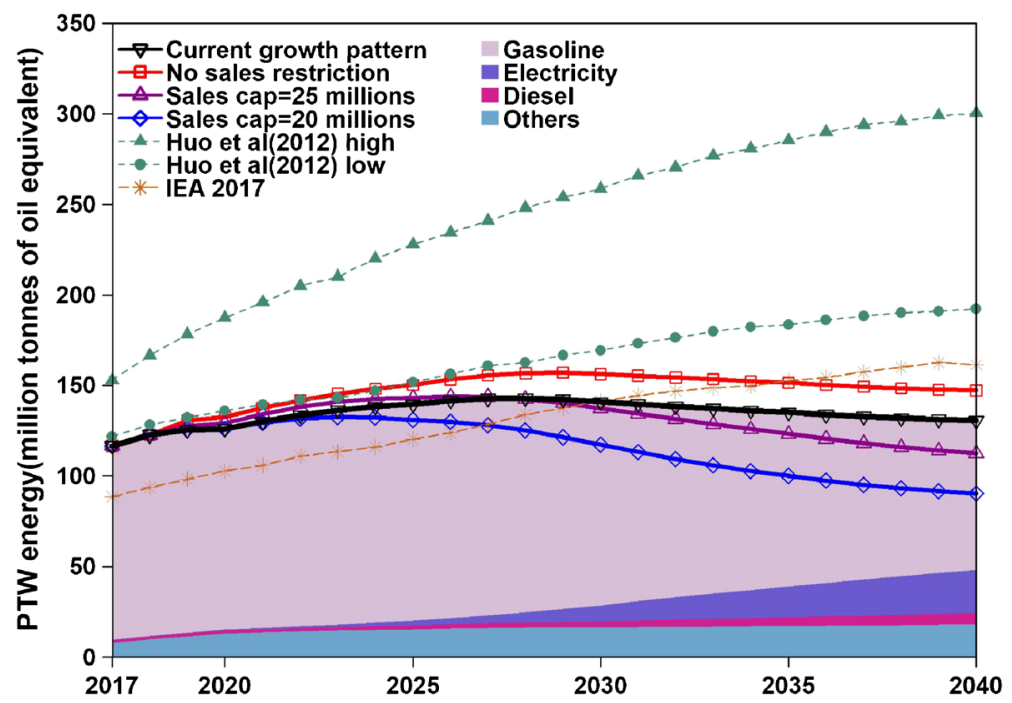

Fig. 9 Projections of PTW energy consumption of private car fleet in China through 2040 under different scenarios 

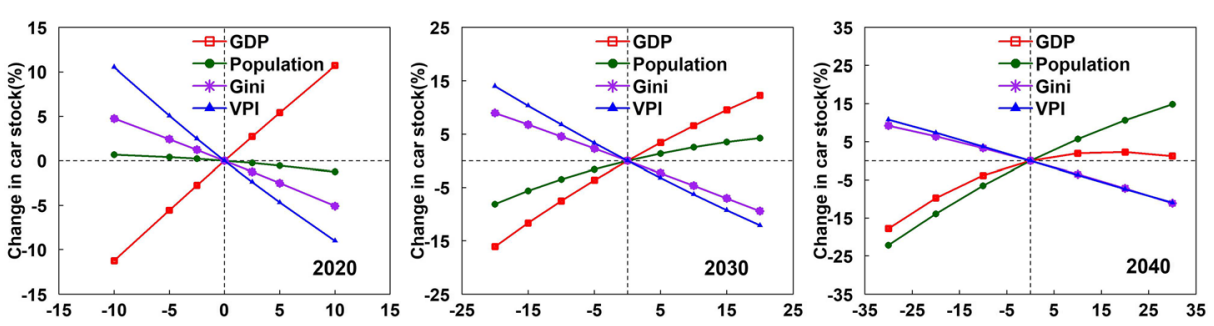

Fig. 10 Sensitivity of private car stock projections to GDP, total population, Gini index, and VPI for the "current growth pattern" scenario as projected to 2020,2030 , and 2040

\section{Conclusions}

In this work, we estimated the private car ownership growth pattern of China by analyzing more than 6300 pairs of car ownership and income data collected from various official statistics at the national, provincial, and city levels in the period of 1997-2017. With the regressed private car ownership growth curves, we projected the stocks, sales, and PTW energy consumption of private cars in China through 2040. Since the ongoing and potentially expanding car sales restrictions would directly affect private car sales and stocks in China, the study also included discussion of the effects of different car sales restriction scenarios. With the analysis of massive and up-to-date statistical data, as well as detailed considerations of the ongoing car sales restrictions, the study provided the latest insights on private car growth in China.

The results showed that the private car stock of China would reach 346 (301-384) and 403 (340-464) million in 2030 and 2040, respectively, while the annual sales would grow to 29 (27-33) million by 2030 and remain stable afterward, if the current growth pattern of car ownership continues. Without car sales restrictions, the private car stock was projected to be 455 million, and the annual private car sales would reach 34 million by 2040 . In the hypothetical national car sales cap scenarios, the private car stock would be stable at $\sim 280$ and $\sim 350$ million by 2040 for the annual sales caps of 20 and 25 million, respectively. PTW energy consumption of the private car fleet was projected to be $131,147,90$, and 113 million toe by 2040 for scenarios of the current growth pattern, no sales restriction, the 20 million sales cap, and the 25 million sales cap, respectively. Comparisons of different car sales restriction scenarios demonstrate the effectiveness of the restriction policy on the control of private car stocks and the reduction of PTW energy consumption in China.

The analysis of the historical and future trend of vehicle population growth in China reveals that the control of private car sales, in addition to the simultaneous improvement of public transportation system, could be an effective strategy to reduce energy consumption and thus greenhouse gas emissions of the China vehicle fleet. Compared to the practices of other cities and provinces in China, Shanghai took a proactive intervention of sales restriction at the early stage of motorization, which improves the effectiveness of measures and reduces social resistances on the sales restriction policy. These experiences would benefit the development of sustainable transportation system in other cities of developing countries, particularly the highly populated cities with relatively low levels of car ownership but high growing potential of motorization. However, the sales restriction is a double-edged sword. It suppresses the vehicle sales and production, which may restrain the development of the automotive industry. 
It also limits the options of private transportation, pushing individuals to meet their transportation needs through public transportation and other mobility services.

Funding information This work was supported by the Aramco Services Company under an agreement through United States Department of Energy Contract No. DEAC02-06CH11357.

\section{References}

BSB (Beijing Statistical Bureau) (2012) Beijing statistical yearbook 2012. Beijing, China

CATRC (China Automotive Technology and Research Center) (1991-2016). China automotive industry yearbook 1991-2016. CAM Association, Tianjin, China

Chen J, Fang F, Hou W, Li F, Pu M, Song M (2015) Chinese Gini coefficient from 2005 to 2012, based on 20 grouped income data sets of urban and rural residents. J Appl Math 2015:939020. https://doi.org/10.1155 $/ 2015 / 939020$

CSAE (Chinese Society of Automotive Engineers) (2016) Technology roadmap for energy saving and new energy vehicles. CM Press, Beijing

Dargay J, Gately D (1999) Income's effect on car and vehicle ownership, worldwide: 1960-2015. Transp Res A Policy Pract 33:101-138

Davis SC, Diegel SW, Boundy RG (2009) Transportation energy data book. In: Oak Ridge National Laboratory, Tennessee

EC (European Commission) (2010). EU energy and transport in figures 2003-2009. Luxembourg

EIA (Energy Information Administration) (2017). International energy outlook 2016. Washington, DC, USA

Gan Y, Griffin WM (2018) Analysis of life-cycle GHG emissions for iron ore mining and processing in Chinauncertainty and trends. Resour Policy 58:90-96

Gan Y, Lu Z, Cai H, Zhou Y, Wang M, He X, Przesmitzki S (2019) Projecting stock and energy consumption of trucks in China through 2050. Transportation Research Board 98th Annual Meeting, Washington DC, United States, January 14, 2019

He K, Huo H, Zhang Q, He D, An F, Wang M, Walsh MP (2005) Oil consumption and $\mathrm{CO}_{2}$ emissions in China's road transport: current status, future trends, and policy implications. Energy Policy 33:1499-1507

HSB (Hainan Statistical Bureau) (2018). Hainan statistical yearbook 2018. Beijing, China

Hsieh I-YL, Kishimoto PN, Green WH (2018) Incorporating multiple uncertainties into projections of Chinese private car sales and stock. Transp Res Rec 2672:182-193. https://doi.org/10.1177/0361198118791361

Huo H, Wang M (2012) Modeling future vehicle sales and stock in China. Energy Policy 43:17-29

Huo H, Wang M, Johnson L, He D (2007) Projection of Chinese motor vehicle growth, oil demand, and $\mathrm{CO}_{2}$ emissions through 2050. Transp Res Rec 2038:69-77

Huo H, Wang M, Zhang X, He K, Gong H, Jiang K, Jin Y, Shi Y, Yu X (2012) Projection of energy use and greenhouse gas emissions by motor vehicles in China: policy options and impacts. Energy Policy 43:37-48

Huo H, Zheng B, Wang M, Zhang Q, He K-B (2015) Vehicular air pollutant emissions in China: evaluation of past control policies and future perspectives. Mitig Adapt Strateg Glob Chang 20:719-733

IEA (International Energy Agency) (2017) Mobility model, version 2017. www.iea. org/etp/etpmodel/transport/. Accessed 15 March 2019

Jong GD, Fox J, Daly A, Pieters M, Smit R (2004) Comparison of car ownership models. Transp Rev 24:379_ 408

Kahm M, Hasenbrink G, Lichtenberg-Fraté H, Ludwig J, Kschischo M (2010) Grofit: fitting biological growth curves with R. J Stat Softw 33:1-21. https://doi.org/10.18637/jss.v033.i07

Kobos PH, Erickson JD, Drennen TE (2003) Scenario analysis of Chinese passenger vehicle growth. Contemp Econ Policy 21:200-217

Lu Z, Zhou Y, Cai H, Wang M, He X, Przesmitzki S (2018) China vehicle fleet model: estimation of vehicle stocks, usage, emissions, and energy use-model description, technical documentation, and user guide. Argonne National Laboratory ANL/ESD-18/15, Argonne, IL, USA

McDonald JB (2008) Some generalized functions for the size distribution of income. In: Chotikapanich D (ed) Modeling income distributions and Lorenz curves. Springer, New York, pp 37-55

McDonald JB, Ransom MR (1979) Functional forms, estimation techniques and the distribution of income. Econometrica 47:1513-1525

NBSC (National Bureau of Statistics of China) (1981-2017). China statistical yearbook 1981-2017. Beijing, China 
NBSC (National Bureau of Statistics of China) (2018). China statistical yearbook 2018. Beijing, China

OICA (International Organization of Motor Vehicle Manufacturers) (2015). 2005-2015 Sales Statistics. http://www.oica.net/category/sales-statistics/. Accessed 15 March 2019

SBJ (Statistics Bureau of Japan) (2007). Japan statistical yearbook 2007. Tokyo, Japan

Souma W (2001) Universal structure of the personal income distribution. Fractals 9:463-470

TSB (Tianjin Statistical Bureau) (2014) Tianjin statistical yearbook 2014. Tianjin, China

UN (United Nations) (2017). World Population Prospects, 2017 Revision. https://esa.un.org/unpd/wpp/. Accessed 15 March 2019

Wang M, He D (2000) The effect of growth of vehicle population and its oil consumption on $\mathrm{CO}_{2}$ emission in China in the future 30 years. Conference for Background of Vehicular Fuel Economy in China, Beijing, China, December, 2000

Wang M, Huo H, Johnson L, He D (2006). Projection of Chinese motor vehicle growth, oil demand, and $\mathrm{CO}_{2}$ emissions through 2050. Argonne National Laboratory ANL/ESD/06-6, Argonne, IL, USA

Williams SE, Davis SC, Boundy RG (2017). Transportation energy data book: edition 36. Oak Ridge National Laboratory, Tennessee, USA

Yan X, Crookes RJ (2009) Reduction potentials of energy demand and GHG emissions in China's road transport sector. Energy Policy 37:658-668

Yin M, Bertolini L, Duan J (2015) The effects of the high-speed railway on urban development: international experience and potential implications for China. Prog Plan 98:1-52

Zhang M, Chen J, Pu M (2013) The research on urban resident income distribution function. J Quant Tech Econ 30:57-71

Zwietering M, Jongenburger I, Rombouts F, Van't Riet K (1990) Modeling of the bacterial growth curve. Appl Environ Microbiol 56:1875-1881

Publisher's note Springer Nature remains neutral with regard to jurisdictional claims in published maps and institutional affiliations.

\section{Affiliations}

\section{Yu Gan ${ }^{1} \cdot{\text { Zifeng } \mathrm{Lu}^{1} \cdot \text { Hao Cai }}^{1} \cdot$ Michael Wang $^{1} \cdot \mathrm{Xin}^{\mathrm{He}}{ }^{2} \cdot$ Steven Przesmitzki $^{2}$}

\section{Zifeng $\mathrm{Lu}$}

zlu@anl.gov

1 Energy Systems Division, Argonne National Laboratory, 9700 S Cass Ave, Lemont, IL 60439, USA

2 Aramco Research Center-Detroit, Aramco Services Company, 46535 Peary Ct, Novi, MI 48377, USA 